Instructions for authors, subscriptions and further details:

http://rasp.hipatiapress.com

\title{
Trascender el Impacto del Dolor Ajeno: Más Allá del World Press Photo
}

Alicia Blázquez ${ }^{1}$

1) Universitat de Barcelona. España

Date of publication: June $3^{\text {th }}, 2017$

Edition period: February 2017- June 2017

To cite this article: Blázquez, Alicia. (2017). Trascender el Impacto del Dolor Ajeno: Más Allá del World Press Photo. Barcelona, Research, Art, Creation, 5(2), 189-202. doi: 10.17583/brac.2017.2031

To link this article: http://dx.doi.org/10.17583/brac.2017.2031

\section{PLEASE SCROLL DOWN FOR ARTICLE}

The terms and conditions of use are related to the Open Journal System and to Creative Commons Attribution License (CC-BY). 


\section{Transcending the Pain of Others: Beyond the World Press Photo}

Alicia Blázquez

Universitat de Barcelona.

(Received: 29 March 2016; Accepted: 8 November 2016; Published: 3 June 2017)

\section{Abstract}

The World Press Photo exhibition brings together, every year during the last eleven, the more representative set of photojournalism of the previous year. The collection of the winners in each edition represents, if one so wishes, an opportunity to reflect on the impact of the images in the public observer, beyond the aesthetic judgment in a particular time and space. This article aims to leave an open window to reflection. An approach on how snapshots shown are supported by three points: the photographer, the spectator and the surrounding social context. A triangle that inevitably possesses a constant ethical conflict: the duty between informing or helping, being anesthetized through the "compassion fatigue" or go beyond the initial discomfort when observing the pain of others and react against it. Human frailty observed as a driver or a deterrent of a broader social action; beyond the photographer, beyond the visit to an exhibition.ext of the abstract.

Keywords: photojournalism, exhibition, observer, pain, action 


\section{Trascender el Impacto del Dolor Ajeno: Más Allá del World Press Photo}

Alicia Blázquez

Universitat de Barcelona.

(Recibido: 29 marzo 2016; Aceptado: 8 noviembre 2016; Publicado: 3 junio 2017)

\section{Resumen}

La exposición del World Press Photo reúne, cada año desde hace once, al conjunto de fotoperiodismo más representativo del año anterior. El recorrido de los premiados en cada edición supone, si uno así lo quiere, una oportunidad de reflexión sobre el impacto de las imágenes en el público observador, más allá del juicio estético en un tiempo y espacio concretos. Este artículo pretende dejar una ventana abierta hacía dicha reflexión. Un planteamiento sobre como las instantáneas mostradas son sostenidas por tres vértices: el fotógrafo, el espectador y el propio contexto social que los envuelve. Un triángulo que plantea ineludiblemente un conflicto ético constante: el deber entre documentar o ayudar, anestesiarse tras la compassion fatigue o trascender la incomodidad inicial al observar el dolor ajeno y movilizarse ante él. La fragilidad humana observada como impulsor o disuasor de una acción social más amplia; más allá del fotógrafo, más allá de la visita a una exposición.

Palabras clave: fotoperiodismo, exposición, observador, dolor, acción 


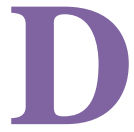

omingo tarde, la cola empieza tímidamente a prolongarse por la rampa de entrada. Los cuerpos de los visitantes se acompasan, siguiendo una misma coreografía, recordando la de Maya Deren en Ritual in transfigured time de 1946. Se miran, se tocan, se acercan, se alejan, se balancean siguiendo el ritmo, de forma indirecta, repetitiva, mecánica con fuerza (Laban, 1987) pero sin vincularse, más allá del compartir un no-lugar (Augé, 1993). Esos "no lugares" a través de los cuales Augé supo expresar la soledad del anonimato urbano. Estaciones de tren, aeropuertos, autopistas, ...y también, porque no, un espacio expositivo. Lugares de tránsito diario de decenas, en ocasiones miles, de personas que se encuentran, se cruzan, dispersan pero apenas interactúan, manteniendo este desconocimiento identitario, muchas veces buscado, de lo que les rodea. A pesar de predominar el no mirarse, la fotografía en este lugar con luz tenue que parece evocar un contexto solemne e íntimo, hasta cierto punto simbólico, se convierte en una relación social; un espacio de encuentro en el cual la propia identidad no puede disociarse del contexto socio histórico que la contiene (Gergen, 1994). Donde se intercalan aspectos de la persona como individuo y características que la asemejan o diferencian de sus coetáneos, la identidad social, aspecto éste último que a modo de espejo, refleja nuestro self (Cooley, 1902). La tierra, la cultura y la política en las que vive una persona influyen tanto en su paisaje psíquico y son tan merecedoras de consideración en este sentido como su propio ambiente subjetivo (Pinkola, 2001).

Después de una espera razonablemente tediosa, aumentando la expectación para recordar lo que nos deparaba el 2014 en los rincones más lejanos (no hay que olvidar que las imágenes expuestas son sobre el año anterior), el World Press Photo 2015 con sus fotografías nos abre una ventana al mundo (INBA, 1989). Una ventana tan indiscreta como la que a través de la cual James Stewart, en su silla de ruedas, miraba sin intervenir. Cierta sensación de desasosiego acompaña, palpable y se hace más densa al adentrarse por el pasillo central, conscientes que la exposición no será un momento para divertirse. Sólo es necesario leer las primeras notas que resumen en unos pocos parágrafos el proceso vital de personas aparentemente como nosotros, aunque mayoritariamente menos afortunadas. Gran parte del público parece entretenerse más con estos 
textos que delante de la imagen, casi indiferente frente a la mirada externa. La consideración de Sarah Thornton respecto a las personas y el arte, como animales sociales que tienen la tendencia (de manera consciente $e$ inconsciente) a agruparse según cierto consenso (Thornton, 2010, p. 39) parece plantearse asimismo en el World Press Photo; es decir que, el considerar valioso artísticamente fuera un juicio subjetivo del espectador en un tiempo y espacio concreto. Una apreciación estética que no tan sólo va modelándose a medida que las imágenes desfilan ante nosotros, sino que es previa y hasta cierto punto compartida, y se materializa en un espacio como el CCCB. Un gran número de personas menos interesadas, aparentemente, por la calidad fotográfica del artista que por esta visión privilegiada, no sólo de las miserias humanas sino también, quizás más que en años anteriores, de la capacidad de lucha y superación.

Esta undécima edición de la exposición internacional World Press Photo, organizada por la Fundación Photografic Social Vision, fundación privada sin ánimo de lucro, inició su andadura en Amsterdam en 1955 de la mano de Kees Scherer, Bram Wisman y Ben Van Meerendonk, con el propósito de resaltar la fotografía de prensa holandesa internacionalmente. Para ello, organizaron un premio al que concurrieron 150 fotógrafos de 9 países. Actualmente, a través de un concurso, un jurado sigue seleccionando aquellas fotos que representan el mejor fotoperiodismo anual a nivel internacional. Una idea de la gran transcendencia de esta convocatoria, sólo en el World Press Photo del 2014 habían participado 5.754 fotógrafos de 132 países con 98.671 fotos.

Recordando esa edición 2014, el recorrido iniciaba de forma directa, con el retrato de violencia doméstica de Sara Lewkowicz o Carlos Arredondo tratando de salvar a los afectados por las dos bombas de la Maratón de Boston (John Tlumacki). Seguía con fotos directas, mostrando la realidad en su máxima dureza, sin ahorrar al espectador; mutilados y muertos desfilando cruda y punzantemente. Uno podría llegar a plantearse hasta qué punto cuanto más exótico es el lugar de la matanza, más ajeno a nuestra cotidianidad, más expuestos estamos a ver frontalmente esos cuerpos inertes. Si esos cuerpos en contextos que no sentimos nuestros, sin parámetros cercanos y disímiles a nuestra realidad próxima, nos permiten un desapego de la atrocidad representada (Sontag, 2003). 
Retomando Sarah Lewkowicz (2013), ésta siguió de cerca la relación de Shane (recién salido de prisión) y su pareja Maggie durante semanas, para ver cómo afectaba en la convivencia el estigma de ser un exconvicto. Una noche, Shane agredió a Maggie y el propósito inicial del proyecto cambió. Lewkowicz fue censurada por un amplio sector de la crítica que consideró que si bien el fotógrafo tiene el deber profesional de documentar las injusticias que presencia, eso nunca debe anteponerse a la ayuda a una víctima.

De hecho, ese conflicto ético siempre ha estado presente en el día a día del fotoperiodista. Ya en 1994, la portada de Kevin Carter en el New York Times de una niña agonizando de inanición en cuclillas con un buitre acechando a sus espaldas perturbó nuestros pensamientos, todavía hasta entonces vírgenes al impacto de la realidad más cruel mediatizada (Maizland, s.d.). Si bien algunos de sus contemporáneos apreciaron los esfuerzos de Carter por denunciar globalmente los problemas de hambruna en esa área, muchos lo criticaron y lo apodaron como el "auténtico buitre" de la situación al no haber ayudado a la niña. Él negó haber estado pasivo durante la situación y manifestó reiteradamente su indefensión ante la magnitud del problema. Cabría preguntarse si debe responsabilizarse al fotoperiodista, como individuo, de problemáticas sociales comunes. Si éstos deben ser los únicos portadores, como observadores directos, de llevar la carga emocional de la muerte, el dolor, la tragedia. Las frase del fotógrafo Gary Winogrand, la fotografía no es mi problema,...es vuestro se hizo célebre tras el ensayo de Danchev (2009). Quien documenta la miseria no puede asumir por si sólo el cambio del mensaje transmitido, las estructuras que sostienen el horror son mucho más complejas (Linfield, 2010).

El fotoperiodista a menudo es testigo de acontecimientos en los que su propia presencia tiene un impacto innegable, pudiendo incluso desencadenar una situación de mayor hostilidad. Especialmente en un campo donde la tensión es permanente, en guerras o desastres, puede encontrarse a menudo con el dilema de disparar su cámara o ayudar a la persona que está a punto de morir. O incluso, en ocasiones, salvaguardar su propia integridad. De hecho, las experiencias traumáticas vividas pueden llegar a afectarle no sólo a nivel físico, sino también psicológico, manifestándose en cuadros de estrés postraumático, provocando reacciones 
de alerta e hipervigilancia una vez fuera de peligro (Feinstein, Owen \& Blair, 2002). En palabras de la fotoperiodista australiana Tamara Dean (Busst, 2012)

Realmente afecta a la gente personalmente, pero no en un modo que hasta ellos lo reconozcan. Y definitivamente, pienso particularmente que los hombres y mujeres que hayan estado en situaciones donde hay pobreza y sufrimiento extremo; eso puede afectar tu percepción de vivir en un mundo confortable y sobre lo que es el dolor. (p.180)

No sólo presencia el conflicto sino también puede llegar a vivirlo internamente. Pero el profesional tiene como responsabilidad contar historias, y hacerlo hasta que la sociedad se implique De ahí la necesidad de un cierto control emocional que le permita mantener una relativa distancia y objetividad (Busst, 2012).

Sin embargo, autoras como Susan Sontag tienen una visión menos benevolente de las intenciones del fotoperiodismo; para ella, fotografiar implica un acto de no acción, donde la fotografía tiene preferencia: la persona que interviene no puede grabar, la persona que está grabando no puede intervenir (Sontag, 1973, p.8). Existe una cierta complicidad entre el fotógrafo que en alguna medida espera que la situación que está aguardando con su cámara se mantenga hasta que él pueda sacar una buena toma, ya que lo que hace interesante, según Sontag, en ese momento al sujeto a fotografiar, es su dolor y/o desgracia (Sontag, 1973)

Sufrir es una cosa; otra cosa es vivir con las imágenes fotografiadas del sufrimiento, que no necesariamente refuerzan la conciencia ni la habilidad de ser compasivo. Puede también corromperles. Una vez uno ha visto tales imágenes, se empieza a ir hacía el camino de ver más y más $[\ldots]$ Las imágenes anestesian. (p. 15)

¿El fotógrafo en primera instancia, y posteriormente el espectador, se aflige ante lo que se presenta ante él e intenta (infructuosamente en demasiadas ocasiones) actuar en consecuencia o permanece impasible? El fotoperiodismo no se resumiría simplemente a dicha cuestión dicotómica. Éste también puede convertirse en una oportunidad para "atravesar" a un mayor público, promoviendo un alcance global de la problemática social 
retratada. Los que sufren quieren tener su historia presente en la comunidad internacional (Ben Bohane en Busst, 2012, p.123). Bleasdale escribió en su artículo sobre su estancia en la República Democrática del Congo que su deber como periodista era confortar al afligido y afligir al confortable. Ir más allá de la ayuda al individuo presente, y tener un impacto directo en el cambio de actitud de la opinión pública ante las injusticias y tragedias ajenas (Bleasdale, 2004) ¿Se puede afirmar que el fotógrafo en situaciones de conflicto es un símbolo de esperanza porque a través de ese testimonio las personas menos privilegiadas sienten cierto alivio al ser escuchadas, perciben que todavía a alguien le importa lo que les pasa? Porque a fin de cuentas no es tanto a quien le emocione sino a quien le haga actuar (Cooper, 2013).

Para aliviar el dilema con el que se enfrenta el fotoperiodista ante la tragedia ajena, la Asociación de Fotógrafos de Prensa Nacional (NPPA) estableció un código ético para promover la mayor veracidad, en todos los formatos, del periodismo visual y así mejorar la confianza del público del material mostrado. En la era digital, la credibilidad sobre las imágenes cada vez es más cuestionada (Mäenpää, 2014). Joe Rosenthal's, con su bandera al viento en Iwo Jima en 1945, tardó un tiempo en confesar que había "construido" la instantánea. Se supone que en ese caso, el profesional debe evitar intencionadamente contribuir, alterar o buscar influir en los acontecimientos que está documentando (NNPA, 2006). Tal como la fotoperiodista Nancy L. Ford dice (Ford 1998, citado en Bersak, 2006)

El trabajo de un fotoperiodista es salir y experimentar la vida por los demás, capturar un acontecimiento en una película, con suerte capturar la emoción que fue experimentada, para que los lectores puedan a su vez ver y sentir lo que era estar ahí. El fotoperiodista debe capturar la verdad también; eso significa que el fotógrafo sólo debe fotografiar lo que ocurrió, cuando ocurrió y no recrear la situación si no llegó a tiempo. (p.53)

La anhelada objetividad del fotoperiodista la comparaba Cartier-Bresson con ser una mosca en la pared, sin ningún impacto ni influencia en la situación (Cartier-Bresson en Lester, 1991). Aunque algunos insisten en 
que en el "gran" fotoperiodismo no muestra, sino que expresa, no alejándose de una visión "artística” (Bowers, 2008).

Volviendo al World Press Photo, en la exposición del año pasado también se encadenaban imágenes algo más sutiles que en ediciones anteriores, como la de Julius Schrank que mostraba con hilaridad e irreverencia unos soldados del ejército Kachin bebiendo y cantando en el funeral de un comandante; u otras que sugerían más que desvelaban como la de Alessandro Penso que, con poco más que unas sábanas y una silla central, enmarcaba la realidad de los refugiados sirios. Sontag creía que toda situación, para despertar interés, debía ser convertida en un espectáculo (Sontag, 2003). En este sentido son destacables las poéticas, no por ello menos explícitas, imágenes del ganador John Stanmeyer en la Edición 2014 en la que vemos una playa repleta de inmigrantes africanos en la costa de Djibouti alargando el móvil en busca de cobertura o las de Peter Holgersson mostrando una vida incluso esperanzadora, la de la deportista sueca Nadja Casadei participante en los campeonatos mundiales de Heptalón a pesar de ser diagnosticada de cáncer linfático.

Otras fotografías permitían hablar de problemáticas sociales, como las de Abbie Trayler-Smith quién, con sólo 16 años, se sometía a una reducción de estómago por su sobrepeso o la de enfermos mentales en Nigeria, grandes olvidados (Robin Hammon); personas que pierden su anonimato convirtiéndonos en testimonios indiscretos. Por momentos, uno se pregunta dónde está la frontera entre la foto como expresión gratuita, la indiferencia más allá del primer impacto, o si realmente hay un interés de comunicar, de producir un verdadero cambio social (Lipovetsky, 2002).

Cabe destacar como presencia autóctona, al catalán Pau Barrena, ganador en la categoría "observed portraits" con una novia bereber en Afanour, uno de los barrios más pobres del sud-este de Marruecos. En la imagen, ésta iba tapada con un velo esperando a que su prometido fuera a buscarla, se trata de explicar aquello que el gran público no puede ver, como una pequeña ventana que da ojos a quien quiera mirar comenta el propio Barrena.

Este año, en la edición 2015, las 20 personas que formaban el jurado de la Fundación Photographic Social Vision (donde se encuentran miembros de Singapur, UK, Finlandia, Camerún...ningún representante de España) 
escogieron como imagen ganadora la del Fotógrafo danés Mads Nissen "Jon \& Alex", el retrato íntimo de una pareja homosexual en uno de los lugares actualmente más homófobos, San Petersburgo. Más allá de esa foto, se suceden por los pasillos de la exposición los momentos más impactantes inmortalizados durante el 2014: los refugiados amontonados en una embarcación precaria huyendo del conflicto Sirio (Mario Sestini); una prostituta china cabizbaja con los tobillos y muñecas encadenados (Liu Song); un inmigrante con los ojos desorbitados bajo un coche escondiéndose del control de la Guardia Civil en Melilla (Gianfranco Tripodo); esos mismos ojos llenos de terror que se ven en los enfermos de ébola retratados por Peter Muller, o las niñas de una escuela de Chibok (Nigeria) secuestradas para unirse al estado islámico (Glenna Gordon). Probablemente no sea mucho aventurar que, en la próxima edición, los atentados Yihadistas serán grandes protagonistas de la sala. Otras, si bien menos explícitas, dejan inevitablemente una huella, como la de Bulent Kilic, que retrata magistralmente la mirada vacía de una joven herida sentada en el suelo tras los enfrentamientos con la policía por la muerte de un muchacho en una manifestación contra el autoritarismo de Erdogan.

Por momentos, la exposición da un respiro a la crudeza visual: Thomas Van Houtryve quién con la ayuda de drones es capaz de transmitirnos la fragilidad humana ante cualquier conflicto bélico tomando fotografías de objetivos habituales de los ataques aéreos en el extranjero (casamientos, funerales, prisiones...) esta vez en EUA. Los avances tecnológicos permiten un fotoperiodismo más inmediato y realista (Mullen, 1998). En ciertas de ellas se insinúa más que se desvela, como en la de Sergei Ilnitsky donde aparecen restos de una explosión, platos llenos de polvo, cortinas ensangrentadas.

Otras temáticas se encadenan con textos directos e imágenes aparentemente anodinas: la explotación laboral en China (Ronghui Chen), la soledad en Japón o Russia (Turi Calafato, Andy Roccheli), el desamparo infantil (Asa Sjostrom), la transexualidad en Indonesia (Fulvio Bugani) o la contaminación asiática (Lu Guang).

Y algunas joyas, como las plantas carnívoras de Christian Zegler o en particular las fotografías aéreas del piloto y fotógrafo polonés Kacper 
Kowalski La admiración por la forma surge antes que cualquier comprensión del contenido.

Cabría mencionar también los proyectos de larga duración como el de Darcy Padilla que documenta durante 21 años la autodestrucción de Julie Baird, una toxicómana de Estados Unidos que antes de los 40 ya había sufrido abusos sexuales, maltratos por sus parejas y un contagio de VIH. El texto desolador que acompaña las instantáneas en blanco y negro no le quita la magia a su estética cuidada. Conmueve y abruma, tanto como aquel retrato asimismo en blanco y negro de Susie Linfield de 2010. Una niña dirigiéndose fijamente hacía adelante, con unos ojos algo tristes y vacíos. Sin revelar la cruda realidad que se esconde detrás de esa mirada. Leyendo a Linfield, es cuando descubrimos que esa niña sin nombre forma parte de un grupo de niños torturados y ejecutados en el campo de Khmer Rouge por su supuesto apoyo contra revolucionario.

Sorprende el tono de algunos comentarios del libro de notas al final de la exposición. Mayoritariamente son apreciaciones positivas sobre la exposición del World Press Photo 2015, interesándose por la misma, si bien otras ponen en duda su utilidad remontándonos al dilema ético previamente mencionado:

Aunque existan tantos problemas en el mundo es una lástima que sólo se proponga una mirada del dolor, el odio, el sufrimiento. Me gustaría que hubiera premios para promover un fotoperiodismo, una exposición y demás actividades que conciencie al espectador desde otros lugares. Y que la mirada de cada uno rescate otro tipo de valores. (Tijuana, México)

En comparación con años anteriores, ha sido menos emocionante. Al margen de este comentario, muy recomendable. (Anónimo)

...Causa preocupación encontrarse con ciertas maneras tendenciosas de tratar noticias actuales. Ninguna mención al resurgimiento del neonazismo en Ucrania en el fotoreportaje sobre el conflicto ucraniano. Da miedo pensar que nos olvidamos de una de las grandes lacras del siglo XX. Esperemos que en próximas ediciones mejore el tratamiento, como mínimo neutral, de la información. (Marta)

El año que viene queremos un poco más de color y alegría. (Anónimo). 
Al acabar la exposición, y sin querer caer en un discurso estereotipado, uno podría plantearse si realmente el estar informado cambia la vivencia de los que sufren. Si existe realmente una pasividad y ausencia de perdurabilidad al observar desgracias ajenas en el periódico, en los medios,... actualmente cada vez más presentes tal como afirma Moeller (1999). Según Sontag surge este sentimiento que la barbarie está cada vez más cerca nuestro, de forma más o menos directa.

Y los estados que se llenan de apatía, de anestesia moral o, mucho peor, emocional, se inundan de otros sentimientos, la rabia y la frustración. No podemos pretender hacernos los inocentes cuando vemos como algunos seres humanos son capaces de infligir violencia, más o menos explícita sobre otros [...] A partir de determinada edad nadie tiene derecho a tal ingenuidad y superficialidad, a este grado de ignorancia o amnesia. (Sontag, 2003, p.89)

El filósofo Emmanuel Levinas (Monografías Humanitas, 2004) dijo que ante el sufrimiento ajeno

Cualquier justificación del sufrimiento duplica la violencia hacía el que sufre y no cumple el primer deber ético, es decir, el reconocimiento [...] Ser testigo no es, por tanto, asumir, conectar con o comprender el sufrimiento del otro. Si ese fuera el caso, el sufrimiento podría quedar justificado por el hecho de crear ocasiones "útiles" para las relaciones sociales. Ser testigo es, en cambio, sufrir uno mismo en nombre del otro, una ocasión para un sufrimiento inútil. Este momento secundario del sufrimiento, producido en el testigo al contemplarse en el otro sufriente, está cargado de significado pero carece de utilidad. (p. 18-19)

El empatizar, a través de las imágenes del World Press Photo, con estas víctimas anónimas es, según Sontag (2003), de un cinismo e irresponsabilidad importantes, ya que no hay que olvidar que somos, hoy por hoy, unos espectadores privilegiados del sufrimiento ajeno. Para ella, al sentir cierta empatía, sentimos que no somos cómplices de las causas del dolor. Nuestra simpatía proclama nuestra inocencia así como nuestra impotencia. No debe olvidarse, y ahora en tiempos de crisis más que nunca, que... "nuestros privilegios están ubicados en el mapa de su sufrimiento, y 
pueden estar vinculados...de la misma manera como la riqueza de unos pueden implicar la indigencia de otros.” (p.80).

A pesar de esos estados de frustración, y aunque prevalezca aparentemente una impasibilidad generalizada, sigue existiendo el deseo de informar, de hacer llegar todo aquello que conmueva. David Dare Parker expresó un sentimiento, que ya habido movilizado en su momento a Cartier-Bresson (Busst, 2012) cuando dijo

El mensaje siempre va a ser el mismo. Estamos informando sobre la inhumanidad del hombre por el hombre, sobre la capacidad de recuperación y supervivencia ante situaciones incómodas, sobre desastres naturales, la enfermedad, la pobreza o el hambre, o sobre sociedades autocráticas o corruptas. Las historias sobre las que estamos informando siempre van a ser las mismas historias. Tratan sobre el comportamiento humano, la fragilidad humana. Es por eso que decidimos hacer lo que hacemos. (p.100)

Por ello, más allá de dicho mensaje, buscar alternativas. Sobreponerse a la compassion fatigue, al sentimiento de culpa que hace voltear hacia otro lado. Dejar de sentirse paralizados, incluso hipnotizados, ante la magnitud de la tragedia. Y que el reto de replantearse el propio self y su interacción con lo que le rodea responsabilice no sólo a mirar sino también a actuar (Moeller, 1999).

\section{References}

Augé, M. (1993). Los no lugares. Espacios del anonimato. Una antropología de la sobremodernidad. Barcelona: Gedisa.

Bersak, D.R. (2006). Ethics in Photojournalism: past, present and future. Master of Science in Comparative Media Studies at the Massachussetts Institute of Technology. Disponible en http://web.mit. edu/drb/Public/Bersak_CMS_Thesis_FINAL.pdf

Bleasdale, M. (2004). Weighing the moral argument against the way things work. Nieman Reports 58 (3), 12-7. Disponible en http://niemanrepo rts.org/articles/weighing-the-moral-argument-against-the-way-thingswork/ 
Bowers, P.J. (2008).Through the Objective Lens: the Ethics of Expression and Repression of High Art in Photojournalism. American Communication Journal, 10, 1-27. Disponible en http://ac-journal.org/ journal/pubs/2008/Special\%20Edition\%2008\%20-\%20Aesthetics/Arti cle_5.pdf

Busst, N.V. (2012). Telling Stories to a Different Beat: Photojournalism as a Way of Life. Doctor of philosophy. School of Media and Communication Faculty of Humanities and Social Sciences Bond University. Disponible en http://epublications.bond.edu.au/cgi/view content.cgi? article $=1109 \&$ context $=$ theses

Cartier-Bresson, H. (1952). The decisive moment. New York: Simon \& Schuster.

Cooley, C.H. (1902). Human Nature and the Social Order. New York: Scribner's.

Cooper, A. (2013). Wonk of the Year. American University, Washington, D.C.19 Oct. 2013. Speech.

Danchev, A. (2009). On Art and War and Terror. Edinburgh: Edinburgh University Press.

Feinstein, A., Owen, J.;Blair, N. (2002). A Hazardous Profession: War, Journalists, \& Psychopathology. American journal of psychiatry, 159 (9), $1335-1339$.

Ford, N. L. (1998). Photojournalism vs. Journalism. Disponible en http://nl ford.com/career/journalism.shtml

Gergen, K. (1994). Realidades y relaciones. Barcelona: Paidós.

INBA, Instituto Nacional de Bellas Artes (1989). 30 años de fotoperiodismo internacional: World Press Photo. Guadalajara (Méjico): Museo de Arte Contemporáneo Internacional Rufino Tamayo.

Laban, R. (1987). El dominio del movimiento. Madrid: Fundamentos.

Lester, P. M. (1991). Photojournalism: An Ethical Approach. Hillsdale, New Jersey: Lawrence Erlbaum Associates.

Lewkowicz, S. N. (2013). Photographer as Witness: A Portrait of Domestic

Violence. Time Lightbox. Time Magazine, 27, s.p.

Linfield, S. (2010). The Cruel Radiance: Photography and Political

Violence. Chicago: The University of Chicago Press.

Lipovetsky, G. (2002). La era del vacío. Barcelona: Anagrama. 
Mäenpää, J. (2014). Rethinking Photojournalism. The Changing Work Practices and Professionalism of Photojournalists in the Digital Age. Nordicom Review 35 (2) 91-104. Disponible en http://www.nord icom.gu.se/sites/default/files/kapitel-pdf/nordicom_review_35_2014 _2_pp._91-104.pdf

Maizland, L. (s.d.) The Lenses of Truth: Photographers Moral Responsibility to Document Injustice in Most Situations. Disponible en http://www.a merican.edu/cas/literature/cwp/upload/WaW-Winning-Essay.pdf

Moeller, S. (1999).Compassion Fatigue: How the Media Sell Disease, Famine, War \& Death. New York: Routledge.

Monografías Humanitas (2004). Dolor y sufrimiento en la práctica clínica. Barcelona: Fundación Medicina y Humanidades Médicas.

Mullen, L. (1998). Truth in Photography: Perception, Myth and Reality in the Postmodern World. Thesis Master of Arts. University of Florida. Disponible en http://etd.fcla.edu/etd/uf/1998/amd0040/Leslie.pdf NPPA. The National Press Photographers Association. NPPA Code of Ethics. Disponible en http://www.nppa.org/professional_development/ business_practices/ethics.html

Pinkola, C. (2001). Mujeres que corren con lobos. Madrid: Suma de Letras. Sontag, S. (1973). On Photography. New York: Rosetta Books. Sontag, S. (2003). Regarding the Pain of Others. New York: Farrar, Straus and Giroux.

Thornton, S. (2010). Siete días en el mundo del arte. Barcelona: Edhasa.

Dra. Alicia Blázquez. Profesora de la Facultad de Psicología Contact Address: Facultat de Psicologia de la Universitat de Barcelona. Campus de Mundet. Passeig de la Vall d'Hebron 171, 08035 Barcelona

E-mail address: ablazquez@ub.edu 